\title{
Survey of monitor specification and viewing conditions in breast screening units in the North West of England
}

\section{ABSTRACT}

Introduction: Monitor specification and viewing conditions are important factors affecting image assessment in mammography. This survey evaluates the different viewing conditions and monitor specifications that exist in acquisition and reporting rooms in UK breast screening units.

Methods: Static $(n=10)$ and mobile $(n=2)$ breast screening units were evaluated in North West England. Room illumination levels were measured in 3 locations for each room using a calibrated Lux meter and the specification of 122 monitors recorded. Room layout, wall colour, location and number of doors, windows and light sources were recorded.

Results: In reporting rooms, 90/91 of monitors had similar technical specifications and were compliant to guidelines. The ambient light levels ranged from 10-25.8 lux. The mean illuminance was $12.32 \pm 4.6$ lux. In acquisition rooms, great variances appeared in monitor specification and ambient light levels. The majority of monitors (24/34) had 3 megapixel (MB) optimum resolution but the ambient light level ranged from 10-1020 lux. The mean illuminance was $105.3 \pm 178.8$ lux. The mobile units were consistent with each other and compliant with guidelines.

Conclusion: A lack of consistency and great variances appeared in terms of ambient light levels and monitor specifications in the image acquisition rooms. However, there was excellent consistency among the illumination measurements and the monitors' technical specifications in the reporting rooms.

Implications for practice: This research demonstrates, for the first time, the need for further research and specialised guidelines for acquisition rooms.

Keywords: ambient lighting, monitors, viewing conditions, mammography 


\section{INTRODUCTION}

Mammography is a widely used diagnostic tool for the diagnosis of breast cancer as it can provide valuable diagnostic information. ${ }^{1}$ Globally breast cancer is the second most common type of cancer, with an estimated 1.5 million new cases being diagnosed annually, with 55,000 of these new cases are reported annually in the UK. ${ }^{1}$

Monitor specifications and environmental conditions have the potential to influence the successful interpretation of mammographic images. Sub-optimal monitor specification and environmental conditions can prevent accurate appreciation of image quality. ${ }^{[2-4]}$

For monitors, the resolution, greyscale range and contrast ratio are among the most important attributes to support image interpretation. However, the performance of a human observer is dependent not only on the technical characteristics of the monitor but also by the environmental conditions. ${ }^{5}$ Incorrect room illumination levels are associated with unwanted reflections on the faceplate of the monitor, which can be a source of artefacts. ${ }^{4}$ Direct light sources, such as ceiling and wall lights, can contribute to reflections on the faceplate of monitors. These reflections make image interpretation difficult and are strongly associated with perceived image quality. ${ }^{3}$ For detailed observations and optimal diagnostic performance, it is important that the illumination level and the specification of the monitors in reporting rooms are suitable for this task. ${ }^{2,3}$

The problem is heightened in the acquisition rooms, where the room has dual purpose: image acquisition and technical review of images. The design and use of these rooms led to variation in illumination levels, the orientation of the monitors relative to the position of light sources and windows. This can introduce unwanted reflections on the faceplate of the monitors. Sub-optimal environmental conditions and a lower specification of monitor has the potential to result in sub-optimal technical evaluation of clinical and test object images, that are critical to quality assurance. Potential impacts of poor viewing conditions include an increase in technical recalls due to inadequate appreciation of image quality and pathology, both of which could lead to increased cost to the National Health Service (NHS) and a worse experience for the patient.

According to the regulatory bodies of the United Kingdom, Europe, America and globally, all rooms in the mammography departments should follow guidelines in order to have displays with the best possible technical characteristics and the optimal environmental conditions for image interpretation. ${ }^{3,4,6-9}$ In these guidelines, it is stated that all reporting rooms in mammography should have monitors with at least 5MP optimum resolution and the illumination level in that room should be kept low. ${ }^{3,4,6-9}$ However, a recent review of monitor specifications and viewing conditions in mammography revealed some disagreement regarding acceptable monitor specification. In addition, it was found that illumination levels are not specified for the image acquisition rooms where the majority of the routine quality assurance and quality control tests takes place; including monitor and system checks, image quality tests, artefact and uniformity tests. ${ }^{10,11}$ A lack of clear guidance for room design and technical specification of monitors in acquisition rooms, may result in reduced standards in the clinical workflow and/or quality assurance of the diagnostic process. Without an 
understanding of the current status of these technical and environmental variables, the potential impact is difficult to predict. ${ }^{10}$

The aim of this study was to survey the environmental conditions, including room design, and the specification of monitors in mammography acquisition and reporting rooms.

\section{METHODS AND MATERIALS}

At the time of study, ethical approval was not required according to the NHS Health Research Authority decision tool. Organisational agreement was obtained from all participating units. In total, 10 static breast screening units consisting of 29 acquisition rooms including 31 different monitors and 26 reporting rooms and with 91 different monitors, were evaluated. At the same time, two mobile breast screening units with 3 acquisition rooms and 3 different monitors, were evaluated. All acquisition and reporting rooms were surveyed under normal working conditions. This was ensured via consultation with the practitioners on site. Additionally, all the monitors were categorised according to their optimum screen resolution, screen size, maximum luminance and contrast ratio.

For every room, a careful record of the overall environment was recorded including: i) room layout, ii) colour of the walls, iii) number of doors, iv) type of doors (solid or door with a window), v) number and location of windows, vi) number and position of monitors, vii) number and position of light bulbs, viii) type of bulbs and ix) the layout of each room was recorded. In all rooms, illumination measurements were performed at the centre of each room with the lux meter at a horizontal plane at $100 \mathrm{~cm}$ above the floor and at $30 \mathrm{~cm}$ and at $100 \mathrm{~cm}$ from the faceplate of the monitor using a calibrated RAYSAFE X2 lux meter (Table 1) was used to record illumination. ${ }^{12}$ At each location, three measurements were performed in order to achieve a mean and standard deviation.

Table 1: The technical characteristics of the RAYSAFE X2 lux meter ${ }^{12}$.

\begin{tabular}{ll}
\hline Illuminance & Luminance \\
\hline Range: $0.1-100000$ lux & Range: $0.01-10000 \mathrm{~cd} / \mathrm{m}^{2}$ \\
Resolution: 0.01 lux & Resolution: $0.001 \mathrm{~cd} / \mathrm{m}^{2}$ \\
Uncertainty illuminant: $3 \%$ & Aperture angle: 5 \\
Deviation from Human Eye $\mathrm{V}(\lambda)\left(\mathrm{f}_{1}{ }^{\prime}\right):<3 \%$ & Uncertainty illuminant: $3 \%$ \\
Cosine Deviation $\left(\mathrm{f}_{2}\right):<3 \%$ & Deviation from Human Eye $\mathrm{V}(\lambda)\left(\mathrm{f}_{1}{ }^{\prime}\right):<3 \%$ \\
\hline
\end{tabular}

Finally, all illumination levels and monitors' specifications were assessed for compliance with the regulatory bodies. ${ }^{3,4,6-9}$

\section{RESULTS}

The technical specifications of all monitors and mean ambient light measurements are presented in Table 2 (reporting rooms) and Table 3 (acquisition rooms). In the acquisition 
rooms, 28/32 had a solid door with the remaining 4 room doors containing windows. In the reporting rooms 20/26 had solid doors with 6 room doors containing windows. Wall colours in both acquisition and reporting rooms were consistent (beige or white). Blackout blinds were found covering the windows in 16 acquisition rooms and 12 reporting rooms; 4 acquisition rooms and 1 reporting room had windows without blackout blinds. In 7 acquisition rooms the position of the light source was in front of the faceplate of the monitor and in 27 rooms the light bulbs were positioned above the monitors. In 4 acquisition rooms the windows were facing the faceplate of the monitors when in 9 rooms the windows were next to the monitors. Finally, in 7 of the acquisition rooms the doors were in front of the faceplate of the monitors. Examples of room layout can be seen in Figure 1.

Figure 1: Examples of different room layouts from different acquisition rooms. $L B=$ Light Bulb, $D=D o o r, W=$ Window, $M=$ Monitor. (a), the ambient light measurement at the centre of the room was at 10 lux; (b), the ambient light measurement at the centre of the room was at 635.6 lux; (c), the ambient light measurement at the centre of the room was at $47 \mathrm{lux}$; $(d)$, the ambient light measurement at the centre of the room was 146 lux.
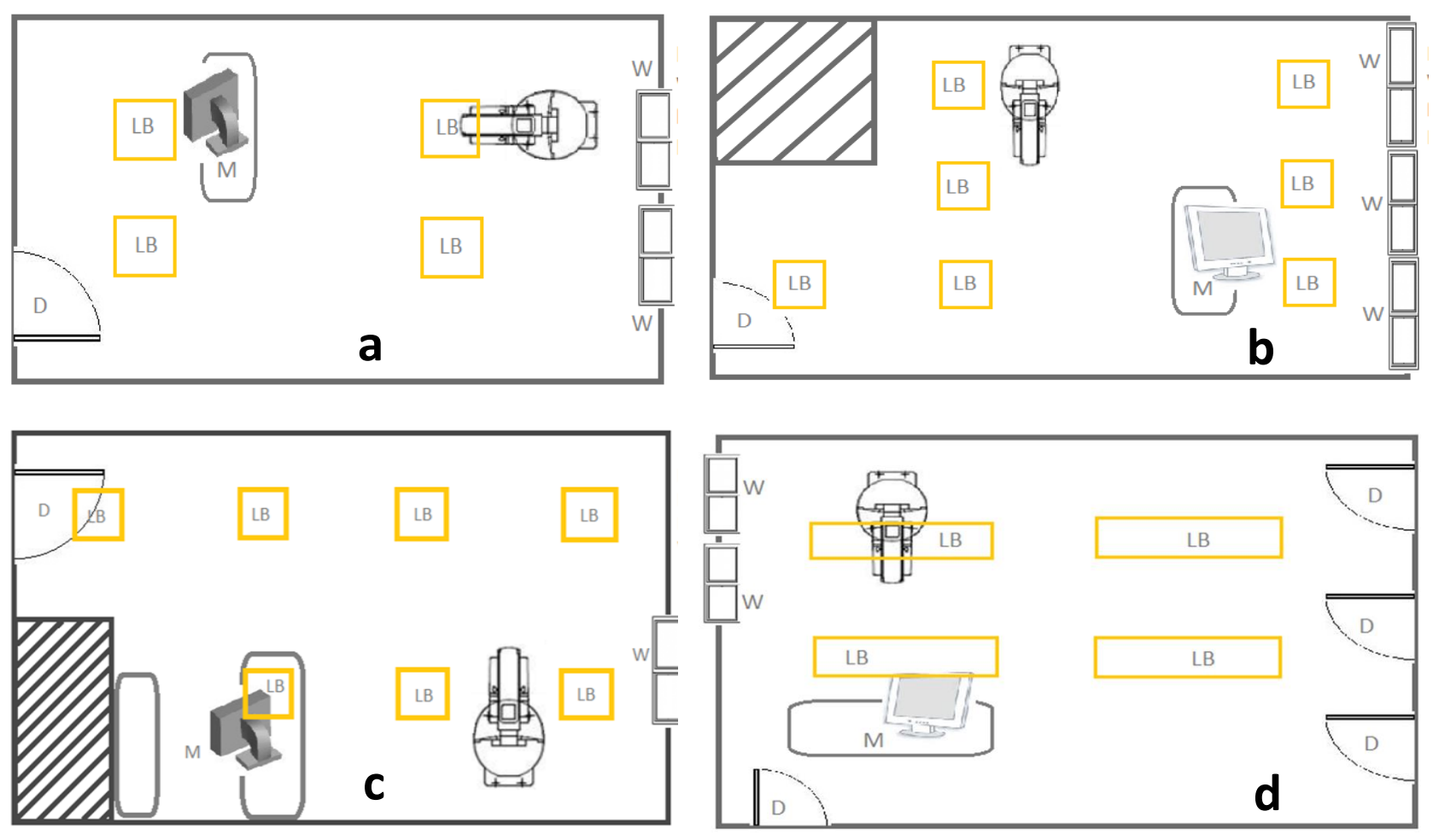
Table 2: Reporting rooms. Monitors' technical specifications and mean values of all ambient light measurements at the centre of the room, at $30 \mathrm{~cm}$ and $100 \mathrm{~cm}$ in front of the monitors.

\begin{tabular}{|c|c|c|c|c|c|c|c|}
\hline \multirow[t]{2}{*}{ Model } & \multirow{2}{*}{$\begin{array}{c}\text { Screen resolution } \\
\text { (megapixels) }\end{array}$} & \multirow{2}{*}{$\begin{array}{l}\text { Screen Size } \\
\text { (inches) }\end{array}$} & \multirow{2}{*}{$\begin{array}{l}\text { Maximum luminance } \\
\left(\mathrm{cd} / \mathrm{m}^{2}\right)\end{array}$} & \multirow[t]{2}{*}{ Contrast ratio } & \multicolumn{3}{|c|}{ Ambient light measurements (lux) } \\
\hline & & & & & Centre of room & At $30 \mathrm{~cm}$ & At $100 \mathrm{~cm}$ \\
\hline EIZO Radiforce GX540 & 5 & 21.3 & 1200 & $1200: 1$ & 10 & 10 & 10 \\
\hline EIZO Radiforce GX540 & 5 & 21.3 & 1200 & $1200: 1$ & 10 & 10 & 10 \\
\hline EIZO Radiforce GX540 & 5 & 21.3 & 1200 & $1200: 1$ & 10 & 10 & 10 \\
\hline EIZO Radiforce GX540 & 5 & 21.3 & 1200 & $1200: 1$ & 10 & 10 & 10 \\
\hline EIZO Radiforce GX540 & 5 & 21.3 & 1200 & $1200: 1$ & 10 & 10 & 10 \\
\hline EIZO Radiforce GX540 & 5 & 21.3 & 1200 & $1200: 1$ & 10 & 10 & 10 \\
\hline EIZO Radiforce RX560 & 5 & 21.3 & 1100 & $1500: 1$ & 10.8 & 10 & 23 \\
\hline EIZO Radiforce RX560 & 5 & 21.3 & 1100 & $1500: 1$ & 10.8 & 10 & 23 \\
\hline EIZO Radiforce RX560 & 5 & 21.3 & 1100 & $1500: 1$ & 16 & 10.2 & 13 \\
\hline EIZO Radiforce RX560 & 5 & 21.3 & 1100 & $1500: 1$ & 16 & 10.2 & 13 \\
\hline NEC MD215MG & 5 & 21.3 & 500 & $850: 1$ & 11.8 & 13 & 17 \\
\hline NEC MD215MG & 5 & 21.3 & 500 & $850: 1$ & 11.8 & 13 & 17 \\
\hline NEC MD215MG & 5 & 21.3 & 500 & $850: 1$ & 11 & 23 & 10 \\
\hline NEC MD215MG & 5 & 21.3 & 500 & $850: 1$ & 11 & 23 & 10 \\
\hline NEC MD215MG & 5 & 21.3 & 500 & $850: 1$ & 10 & 10 & 10 \\
\hline NEC MD215MG & 5 & 21.3 & 500 & $850: 1$ & 10 & 10 & 10 \\
\hline BARCO Coronis & 6 & 30.4 & 1050 & $1500: 1$ & 23 & 14.5 & 20.1 \\
\hline BARCO MDNG-5121 & 5 & 21.3 & 1100 & $850: 1$ & 12.3 & 10 & 12.3 \\
\hline BARCO MDNG-5121 & 5 & 21.3 & 1100 & $850: 1$ & 12.3 & 10 & 12.3 \\
\hline BARCO MDNG-5121 & 5 & 21.3 & 1100 & $850: 1$ & 10 & 10 & 10 \\
\hline BARCO MDNG-5121 & 5 & 21.3 & 1100 & $850: 1$ & 10 & 10 & 10 \\
\hline BARCO MDNG-5121 & 5 & 21.3 & 1100 & $850: 1$ & 12.3 & 10 & 12.3 \\
\hline BARCO MDNG-5121 & 5 & 21.3 & 1100 & $850: 1$ & 12.3 & 10 & 12.3 \\
\hline BARCO MDNG-5121 & 5 & 21.3 & 1100 & $850: 1$ & 10 & 10 & 10 \\
\hline BARCO MDNG-5121 & 5 & 21.3 & 1100 & $850: 1$ & 10 & 10 & 10 \\
\hline
\end{tabular}




\begin{tabular}{|c|c|c|c|c|c|c|c|}
\hline EIZO Radiforce GX530 & 5 & 21.3 & 1200 & $1200: 1$ & 15.2 & 13 & 14.3 \\
\hline EIZO Radiforce GX530 & 5 & 21.3 & 1200 & $1200: 1$ & 15.2 & 13 & 14.3 \\
\hline BARCO MDNG-5121 & 5 & 21.3 & 1100 & $850: 1$ & 10 & 10 & 10 \\
\hline BARCO MDNG-5121 & 5 & 21.3 & 1100 & $850: 1$ & 10 & 10 & 10 \\
\hline BARCO MDNG-5121 & 5 & 21.3 & 1100 & $850: 1$ & 10 & 10 & 10 \\
\hline BARCO MDNG-5121 & 5 & 21.3 & 1100 & $850: 1$ & 10 & 10 & 10 \\
\hline BARCO MDNG-5121 & 5 & 21.3 & 1100 & $850: 1$ & 10 & 10 & 10 \\
\hline BARCO MDNG-5121 & 5 & 21.3 & 1100 & $850: 1$ & 10 & 10 & 10 \\
\hline BARCO MDNG-5121 & 5 & 21.3 & 1100 & $850: 1$ & 10 & 10 & 10 \\
\hline BARCO MDNG-5121 & 5 & 21.3 & 1100 & $850: 1$ & 10 & 10 & 10 \\
\hline EIZO Radiforce GX520 & 5 & 21.3 & 700 & $800: 1$ & 10 & 10 & 10 \\
\hline EIZO Radiforce GX520 & 5 & 21.3 & 700 & $800: 1$ & 10 & 10 & 10 \\
\hline EIZO Radiforce GX530 & 5 & 21.3 & 1200 & $1200: 1$ & 10 & 10 & 10 \\
\hline EIZO Radiforce GX530 & 5 & 21.3 & 1200 & $1200: 1$ & 10 & 10 & 10 \\
\hline EIZO Radiforce GX530 & 5 & 21.3 & 1200 & $1200: 1$ & 10 & 10 & 10 \\
\hline EIZO Radiforce GX530 & 5 & 21.3 & 1200 & $1200: 1$ & 10 & 10 & 10 \\
\hline EIZO Radiforce GX530 & 5 & 21.3 & 1200 & $1200: 1$ & 10 & 10 & 10 \\
\hline EIZO Radiforce GX530 & 5 & 21.3 & 1200 & $1200: 1$ & 10 & 10 & 10 \\
\hline EIZO Radiforce GX530 & 5 & 21.3 & 1200 & $1200: 1$ & 14 & 10 & 10 \\
\hline EIZO Radiforce GX530 & 5 & 21.3 & 1200 & $1200: 1$ & 14 & 10 & 10 \\
\hline EIZO Radiforce GX530 & 5 & 21.3 & 1200 & $1200: 1$ & 14 & 10 & 10 \\
\hline EIZO Radiforce GX530 & 5 & 21.3 & 1200 & $1200: 1$ & 14 & 10 & 10 \\
\hline EIZO Radiforce GX530 & 5 & 21.3 & 1200 & $1200: 1$ & 10 & 10 & 10 \\
\hline EIZO Radiforce GX530 & 5 & 21.3 & 1200 & $1200: 1$ & 10 & 10 & 10 \\
\hline EIZO Radiforce GX530 & 5 & 21.3 & 1200 & $1200: 1$ & 10 & 10 & 10 \\
\hline EIZO Radiforce GX530 & 5 & 21.3 & 1200 & $1200: 1$ & 10 & 10 & 10 \\
\hline BARCO MDNG-5121 & 5 & 21.3 & 1100 & $850: 1$ & 14 & 10 & 10 \\
\hline BARCO MDNG-5121 & 5 & 21.3 & 1100 & $850: 1$ & 14 & 10 & 10 \\
\hline BARCO MDNG-5121 & 5 & 21.3 & 1100 & $850: 1$ & 24.3 & 16.2 & 22.4 \\
\hline
\end{tabular}




\begin{tabular}{|c|c|c|c|c|c|c|c|}
\hline BARCO MDNG-5121 & 5 & 21.3 & 1100 & $850: 1$ & 24.3 & 16.2 & 22.4 \\
\hline EIZO Radiforce GX540 & 5 & 21.3 & 1200 & $1200: 1$ & 24.3 & 15.4 & 25.8 \\
\hline EIZO Radiforce GX540 & 5 & 21.3 & 1200 & $1200: 1$ & 24.3 & 15.4 & 25.8 \\
\hline EIZO Radiforce GX540 & 5 & 21.3 & 1200 & $1200: 1$ & 24.3 & 20.2 & 25.8 \\
\hline EIZO Radiforce GX540 & 5 & 21.3 & 1200 & $1200: 1$ & 24.3 & 20.2 & 25.8 \\
\hline EIZO Radiforce GX540 & 5 & 21.3 & 1200 & $1200: 1$ & 11.8 & 10 & 10 \\
\hline EIZO Radiforce GX540 & 5 & 21.3 & 1200 & $1200: 1$ & 11.8 & 10 & 10 \\
\hline EIZO Radiforce GX540 & 5 & 21.3 & 1200 & $1200: 1$ & 11.8 & 10 & 10 \\
\hline EIZO Radiforce GX540 & 5 & 21.3 & 1200 & $1200: 1$ & 11.8 & 10 & 10 \\
\hline EIZO Radiforce GX540 & 5 & 21.3 & 1200 & $1200: 1$ & 11.8 & 10 & 10 \\
\hline EIZO Radiforce GX540 & 5 & 21.3 & 1200 & $1200: 1$ & 11.8 & 10 & 10 \\
\hline EIZO Radiforce GX550 & 5 & 21.3 & 2000 & 1500:1 & 11.8 & 10 & 10 \\
\hline EIZO Radiforce GX550 & 5 & 21.3 & 2000 & $1500: 1$ & 11.8 & 10 & 10 \\
\hline EIZO Radiforce GS521 & 5 & 21.3 & 700 & $800: 1$ & 11.8 & 10 & 10 \\
\hline EIZO Radiforce GS521 & 5 & 21.3 & 700 & $800: 1$ & 11.8 & 10 & 10 \\
\hline EIZO Radiforce GX550 & 5 & 21.3 & 2000 & 1500:1 & 10 & 12 & 10 \\
\hline EIZO Radiforce GX550 & 5 & 21.3 & 2000 & $1500: 1$ & 10 & 12 & 10 \\
\hline EIZO Radiforce GX550 & 5 & 21.3 & 2000 & $1500: 1$ & 10 & 12 & 10 \\
\hline EIZO Radiforce GX550 & 5 & 21.3 & 2000 & $1500: 1$ & 10 & 12 & 10 \\
\hline EIZO Radiforce GX550 & 5 & 21.3 & 2000 & 1500:1 & 10 & 10 & 10 \\
\hline EIZO Radiforce GX550 & 5 & 21.3 & 2000 & $1500: 1$ & 10 & 10 & 10 \\
\hline EIZO Radiforce GX550 & 5 & 21.3 & 2000 & $1500: 1$ & 10 & 10 & 10 \\
\hline EIZO Radiforce GX550 & 5 & 21.3 & 2000 & $1500: 1$ & 10 & 10 & 10 \\
\hline EIZO Radiforce GX550 & 5 & 21.3 & 2000 & 1500:1 & 10 & 10 & 10 \\
\hline EIZO Radiforce GX550 & 5 & 21.3 & 2000 & $1500: 1$ & 10 & 10 & 10 \\
\hline EIZO Radiforce GX550 & 5 & 21.3 & 2000 & $1500: 1$ & 10 & 10 & 10 \\
\hline EIZO Radiforce GX550 & 5 & 21.3 & 2000 & $1500: 1$ & 10 & 10 & 10 \\
\hline EIZO Radiforce GX550 & 5 & 21.3 & 2000 & $1500: 1$ & 10 & 10 & 10 \\
\hline EIZO Radiforce GX550 & 5 & 21.3 & 2000 & $1500: 1$ & 10 & 10 & 10 \\
\hline
\end{tabular}




\begin{tabular}{|c|c|c|c|c|c|c|c|}
\hline EIZO Radiforce GX550 & 5 & 21.3 & 2000 & $1500: 1$ & 10 & 10 & 10 \\
\hline EIZO Radiforce GX550 & 5 & 21.3 & 2000 & $1500: 1$ & 10 & 10 & 10 \\
\hline EIZO Radiforce GX550 & 5 & 21.3 & 2000 & $1500: 1$ & 10 & 10 & 10 \\
\hline EIZO Radiforce GX550 & 5 & 21.3 & 2000 & $1500: 1$ & 10 & 10 & 10 \\
\hline EIZO Radiforce GX550 & 5 & 21.3 & 2000 & $1500: 1$ & 10 & 10 & 10 \\
\hline EIZO Radiforce GX550 & 5 & 21.3 & 2000 & $1500: 1$ & 10 & 10 & 10 \\
\hline EIZO Radiforce GX550 & 5 & 21.3 & 2000 & $1500: 1$ & 10 & 10 & 10 \\
\hline EIZO Radiforce GX550 & 5 & 21.3 & 2000 & $1500: 1$ & 10 & 10 & 10 \\
\hline
\end{tabular}

Table 3: Acquisition rooms. Monitors' technical specifications and mean values of all ambient light measurements at the centre of the room, at $30 \mathrm{~cm}$ and $100 \mathrm{~cm}$ in front of the monitors

\begin{tabular}{|c|c|c|c|c|c|c|c|}
\hline \multirow[t]{2}{*}{ Model } & \multirow{2}{*}{$\begin{array}{l}\text { Screen resolution } \\
\text { (megapixels) }\end{array}$} & \multirow{2}{*}{$\begin{array}{c}\text { Screen Size } \\
\text { (inches) }\end{array}$} & \multirow{2}{*}{$\begin{array}{l}\text { Maximum luminance } \\
\left(\mathrm{cd} / \mathrm{m}^{2}\right)\end{array}$} & \multirow[t]{2}{*}{ Contrast ratio } & \multicolumn{3}{|c|}{ Ambient light measurements (lux) } \\
\hline & & & & & Centre of room & At $30 \mathrm{~cm}$ & At $100 \mathrm{~cm}$ \\
\hline BARCO MDNG-2121 & 1.9 & 21.3 & 1650 & $850: 1$ & 35.3 & 85 & 56.8 \\
\hline Hologic Selenia & 3 & 21 & N/A & $\mathrm{N} / \mathrm{A}$ & 35.3 & 29.5 & 25.5 \\
\hline EIZO Radiforce RX340 & 3 & 21.2 & 1000 & 1400:1 & 51 & 54.3 & 30.1 \\
\hline EIZO Radiforce RX340 & 3 & 21.2 & 1000 & $1400: 1$ & 51 & 37.3 & 35.6 \\
\hline EIZO Radiforce RX340 & 3 & 21.2 & 1000 & $1400: 1$ & 164 & 70 & 48.8 \\
\hline EIZO Radiforce RX340 & 3 & 21.2 & 1000 & $1400: 1$ & 164 & 80 & 53.7 \\
\hline GE Healthcare 5148720-4 & 1 & 19 & N/A & $\mathrm{N} / \mathrm{A}$ & 47 & 36 & 21 \\
\hline GE Healthcare 5148720-4 & 1 & 19 & N/A & N/A & 163 & 36 & 32.6 \\
\hline GE Healthcare 5148720-4 & 1 & 19 & N/A & $\mathrm{N} / \mathrm{A}$ & 21.2 & 68.8 & 38.2 \\
\hline BARCO Hologic Selenia & 3 & 21 & N/A & N/A & 23.3 & 24 & 23 \\
\hline BARCO Hologic Selenia & 3 & 21 & N/A & $\mathrm{N} / \mathrm{A}$ & 38 & 38.7 & 46.3 \\
\hline BARCO Hologic Selenia & 3 & 21 & N/A & $\mathrm{N} / \mathrm{A}$ & 38.6 & 43.2 & 38 \\
\hline EIZO Radiforce GX340 & 3 & 21.3 & 1200 & $1400: 1$ & 37.2 & 39 & 36 \\
\hline
\end{tabular}




\begin{tabular}{|c|c|c|c|c|c|c|c|}
\hline EIZO Radiforce RX320 & 3 & 21.2 & 900 & $1000: 1$ & 53.3 & 54 & 39 \\
\hline EIZO Radiforce RX320 & 3 & 21.2 & 900 & $1000: 1$ & 10 & 10 & 10 \\
\hline EIZO Radiforce RX320 & 3 & 21.2 & 900 & $1000: 1$ & 119 & 59.8 & 64.5 \\
\hline EIZO Radiforce RX320 & 3 & 21.2 & 900 & $1000: 1$ & 635.6 & 1013.3 & 1020 \\
\hline EIZO Radiforce RX320 & 3 & 21.2 & 900 & 1000:1 & 312 & 412.6 & 404.6 \\
\hline GE Healthcare 5148720-4 & 1 & 19 & N/A & N/A & 214.6 & 531.6 & 602.3 \\
\hline BARCO Hologic Selenia & 3 & 21 & N/A & N/A & 146 & 83 & 89 \\
\hline EIZO Radiforce RX320 & 3 & 21 & $\mathrm{~N} / \mathrm{A}$ & N/A & 72.5 & 45.3 & 32.1 \\
\hline EIZO Radiforce RX320 & 3 & 21 & $\mathrm{~N} / \mathrm{A}$ & N/A & 49 & 28.8 & 31.8 \\
\hline EIZO Radiforce RX320 & 3 & 21.2 & 900 & $1000: 1$ & 37.3 & 35.4 & 37 \\
\hline GE Healthcare 2403951-4 & 1.3 & 18 & N/A & N/A & 59.4 & 13.6 & 12 \\
\hline GE Healthcare 2403951-4 & 1.3 & 18 & N/A & N/A & 549.3 & 182 & 325 \\
\hline BARCO Hologic Selenia & 3 & 21 & N/A & N/A & 59.8 & 125 & 115 \\
\hline BARCO Hologic Selenia & 3 & 21 & $\mathrm{~N} / \mathrm{A}$ & N/A & 68.3 & 44.2 & 29.6 \\
\hline EIZO 10293006 RX320 & 3 & 21 & 400 & 1000:1 & 35.46 & 34.3 & 29.4 \\
\hline Hologic Selenia & 3 & 21 & N/A & N/A & 54.43 & 43.6 & 92.3 \\
\hline Hologic Selenia & 3 & 21 & $\mathrm{~N} / \mathrm{A}$ & $\mathrm{N} / \mathrm{A}$ & 44.83 & 15.4 & 24.8 \\
\hline BARCO MDNG-2121 & 2 & 21.3 & 1650 & $850: 1$ & 36.7 & 58.1 & 126 \\
\hline BARCO MDNG-2121 & 2 & 21.3 & 1650 & $850: 1$ & 40.3 & 37.6 & 24.6 \\
\hline BARCO MDNG-2121 & 2 & 21.3 & 1650 & $850: 1$ & 48.3 & 38.7 & 20.9 \\
\hline
\end{tabular}




\section{Monitor specifications and viewing conditions}

\section{Reporting rooms}

In reporting rooms 90/91 monitors had $5 \mathrm{MP}$ optimum resolution and screen size at $21.3 \mathrm{n}$. Of these 90 monitors, the maximum luminance ranged from $500-2000 \mathrm{~cd} / \mathrm{m}^{2}$ with a large proportion of the monitors with above $1000 \mathrm{~cd} / \mathrm{m}^{2}$, with $24 / 91$ monitors at $2000 \mathrm{~cd} / \mathrm{m}^{2}$. Only 10 monitors were found to have a comparatively lower maximum luminance of 500$700 \mathrm{~cd} / \mathrm{m}^{2}$. The contrast ratio ranged from 800:1 to 1500:1. The remaining monitor had $6 \mathrm{MP}$ optimum resolution, a screen size of $30.4 "$, maximum luminance of $1050 \mathrm{~cd} / \mathrm{m}^{2}$ and the contrast ratio of 1500:1.

The ambient light measurements at the centre of the room ranged from of 10-24.3 lux. In the majority of these measurements (54/91) the illumination level was at 10 lux. At $30 \mathrm{~cm}$ in front of monitors the illumination levels were within a range of 10-23 lux, while 72/91 measurements appeared at 10 lux. Similarly, at $100 \mathrm{~cm}$ in front of monitors 72/91 measurements were found at 10 lux with a range of 10-25.8 lux. The average value at the centre of the rooms was $12.6 \pm 5.0$, at $30 \mathrm{~cm}$ in front of monitor was $11.5 \pm 3.1$ and at $100 \mathrm{~cm}$ was $12.7 \pm 5.3$. From these measurements, box and whisker plots were created (Figure 2). The lower whisker in the box plot diagram cannot be visualised as all values in the first quartile were 10.

Figure 2: Box plot diagram from the ambient light measurements in reporting rooms at the centre of the room, at $30 \mathrm{~cm}$ in front of the monitor and at $100 \mathrm{~cm}$ in front of the monitor. The lower whisker cannot be visualised. The $x$ mark represents the mean values. The dots represent the measurements which are distant from the rest of the data and outside from the above whisker (outliers).

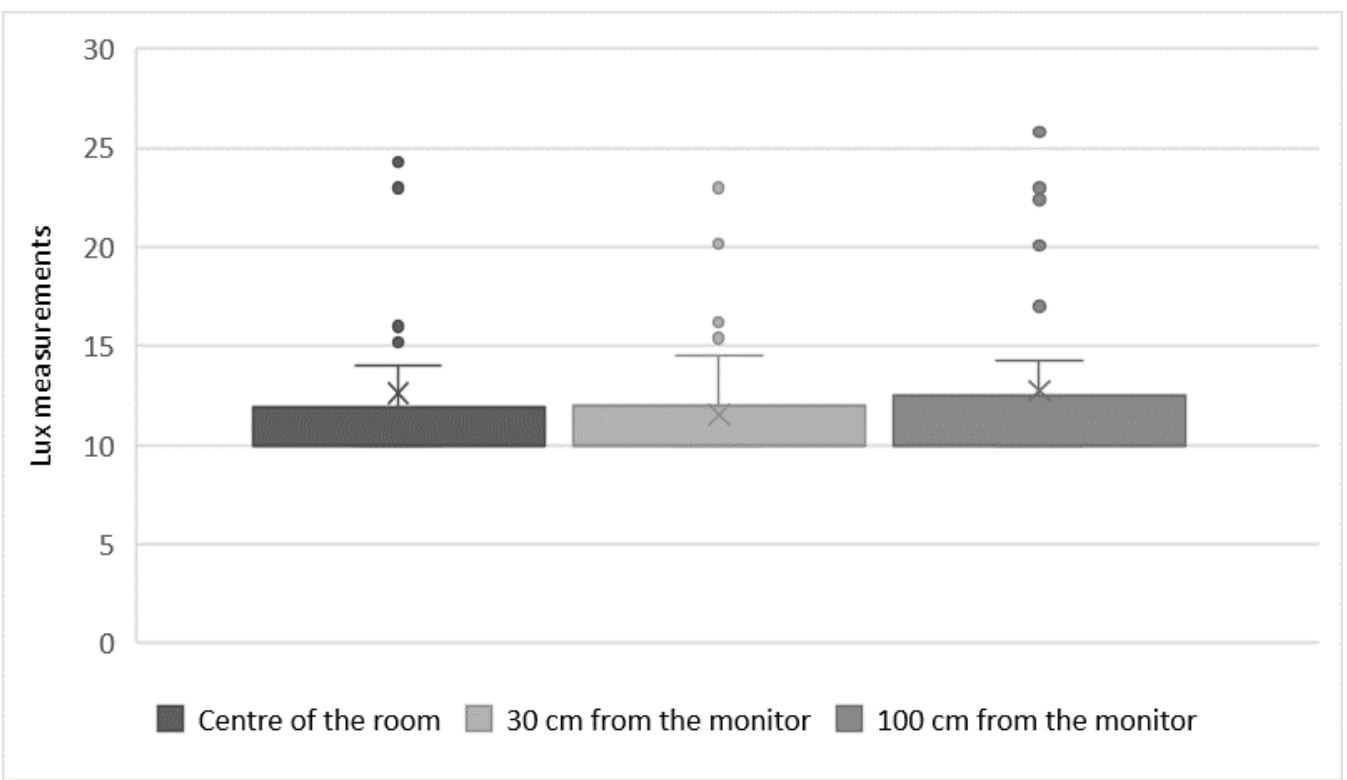




\section{Acquisition rooms}

In the acquisition rooms all monitors had different technical specifications (Table 3) with variations in monitor screen size, maximum luminance and contrast ratio. Monitor size ranged from 18-21.3". The maximum luminance ranged from $400-1650 \mathrm{~cd} / \mathrm{m}^{2}$ and the contrast ratio was within a range of $850: 1$ to $1400: 1$. On the contrary, in mobile units all monitors (3/3) had $2 \mathrm{MP}$ optimum resolution and similar technical specifications $\left(1650 \mathrm{~cd} / \mathrm{m}^{2}\right.$ maximum luminance, 21.3 " screen size and 850:1 contrast ratio). The optimum resolution was found within a range of 1-3MP with a low prevalence of 3MP resolution. 4/34 had 1MP optimum resolution, $2 / 34$ were $1.3 \mathrm{MP}, 1 / 34$ monitor with $1.9 \mathrm{MP}, 3 / 34$ monitors with $2 \mathrm{MP}$ and finally $24 / 34$ monitors with $3 \mathrm{MP}$.

At the centre of the acquisition rooms the ambient light measurements were within the range of 10-635.6 lux, with 11 measurements being less than 38 lux. A box and whisker plot displays the variance in illumination levels at three measured areas (Figure 3 ). At $30 \mathrm{~cm}$ from the monitors' faceplate the illumination levels ranged from 10-1013.3 lux, while 15/34 of measurements appeared less than 39 lux. At $100 \mathrm{~cm}$ from the monitors' faceplate the illumination levels ranged from 10-1020 lux (Figure 3) with the majority of measurements $(21 / 34)$ being less than 39 lux. The average value at the centre of the room was $104.4 \pm 139.9$, at $30 \mathrm{~cm}$ in front of monitor was $104.4 \pm 192.7$ and at $100 \mathrm{~cm}$ was $107.5 \pm 202.9$. In rooms where the light sources (light bulbs and windows) were in front and facing the faceplate of the monitor, a rise in the illumination level was noticed up to $401 \%$ at $30 \mathrm{~cm}$ of the monitor and $393 \%$ at $100 \mathrm{~cm}$ of the monitor relative to rooms where the light sources were behind the faceplate of the monitor.

Figure 3: Box plot diagram from the ambient light measurements in acquisition rooms at the centre of the room, at $30 \mathrm{~cm}$ in front of the monitor and at $100 \mathrm{~cm}$ in front of the monitor. The $x$ mark represents the mean values. The dots represent the measurements which are distant from the rest of the data and outside from the above whisker (outliers).

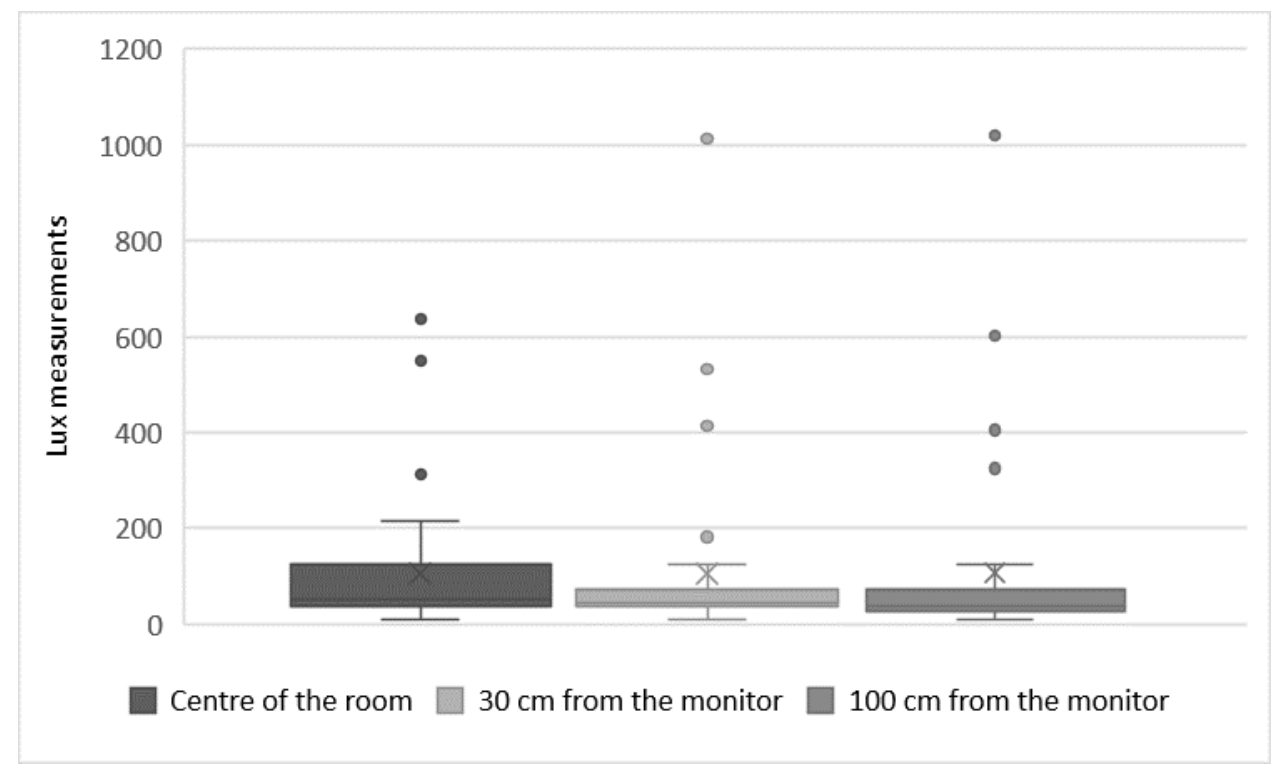




\section{DISCUSSION}

This survey of mammography units in the North West of England found consistency in the environmental conditions and monitor specifications in the reporting rooms and large variations of these factors in acquisition rooms. The outcomes of this survey have been compared to national guidelines in order to explain the level of compliance. According to the existing literature, there is variation in the proposed guidelines from the regulatory bodies. ${ }^{10}$ The majority of the guidelines propose illumination levels above 20 lux for the reporting rooms when at the same time, there is no clear guidance for the acquisition rooms. ${ }^{10}$ The lack of clear guidelines for acquisition rooms is a persisting problem and it can provoke nonuniformity in clinical practice. We consider this a potential area for impact, as the practitioners are using these monitors during the quality assurance and quality control tests and in order to make decisions about the diagnostic performance of the imaging system.

Comparing the results from both acquisition and reporting rooms, it is noted that the reporting rooms show greater consistency in terms of monitor specifications and ambient light levels. On the contrary, the acquisition rooms presented great variances among their monitors and their illumination levels. Room illumination variations were noted where the measurements performed at 30 and $100 \mathrm{~cm}$ in front of the monitors. With respect to the presence of windows in the acquisition rooms, it was apparent that the rooms with windows had an average rise in illumination level up to $177 \%$ at the centre of the room, $322 \%$ at 30 $\mathrm{cm}$ in front of monitors and $473 \%$ at $100 \mathrm{~cm}$ in front of monitors. The presence of a door next to a monitor gave a small rise in illumination at the centre of the room and at $100 \mathrm{~cm}$ in front of the monitor, but a noticeable rise up to $18 \%$ at $30 \mathrm{~cm}$ in front of monitors. Figure $1 \mathrm{~b}$ describes the layout of the acquisition room with the highest illumination levels. The illumination level in that room was up to 635.6 lux at the centre of the room, 1012.3 lux at $30 \mathrm{~cm}$ in front of the monitor and 1020 lux at $100 \mathrm{~cm}$. In the reporting rooms the highest measurement (Figure 4) was 24.3 lux at the centre of the room, 20.2 lux at $30 \mathrm{~cm}$ in front of the monitors and at $25.8 \mathrm{lux}$ at $100 \mathrm{~cm}$. In both rooms, the room layout with the light bulbs in front the faceplate of the monitors and the presence of windows in front to the monitor appear to be the overriding factors for these higher measurements.

Figure 4: Reporting room in the survey. At the centre of the room (b) the ambient light level was at 24.3 lux. $30 \mathrm{~cm}$ in front of monitor (a) the ambient light measurement was at 20.2 lux and at $100 \mathrm{~cm}$ the ambient light was at 25.8 lux. At $30 \mathrm{~cm}$ in front of monitor (c) the ambient light measurement was at 15.4 lux and at $100 \mathrm{~cm}$, at 25.8 lux. At $30 \mathrm{~cm}$ in front of monitor (d) the ambient light measurement was at 16.2 lux and at $100 \mathrm{~cm}, 22.4$ lux.

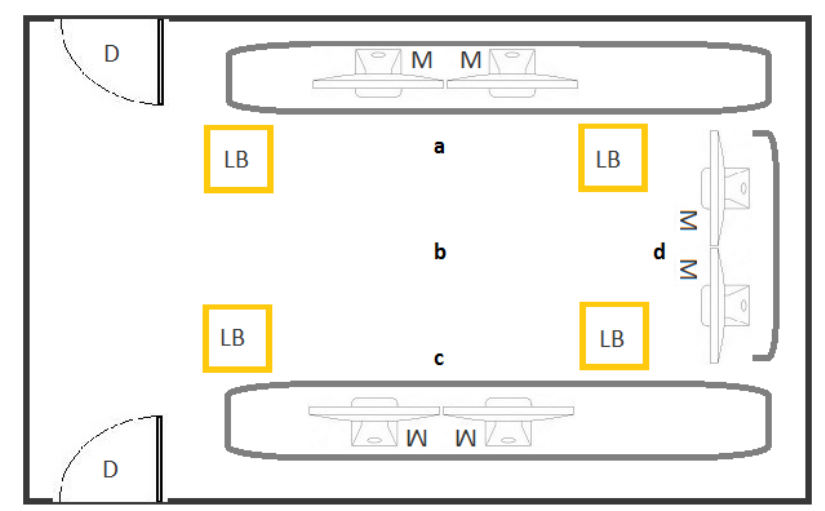


The potential for proper image assessment (optimal assessment of image quality) may be decreased due to poor viewing conditions. These findings are of great importance considering the fact that the illumination in acquisition or reporting rooms affects the evaluation of the mammographic image. ${ }^{7}$ In practice the ambient light reflects off the surface of the monitors and adds luminance to the displayed mammographic image. ${ }^{3}$ Artefacts and loss of image quality are associated with reflections from the display surface. ${ }^{13}$ For this reason, the display devices should always be positioned in a way to minimize specular reflection from direct light sources such as daylight or ceiling lights. ${ }^{3}$

Another interesting finding was that in the majority of the reporting rooms the illumination level in front of the monitor at $30 \mathrm{~cm}$ was less than 20 lux, in line with the recommendations by the American Association of Physicists in Medicine (AAPM), the International Atomic Energy Agency (IAEA), the Royal College of Radiologists (RCR) and the National Health Service Breast Screening Programme (NHSBSP). ${ }^{3,4,6,7}$ At the same time only $8 / 91$ measurements had illumination levels above the 15 lux threshold recommended within the Institute of Physics and Engineering in Medicine (IPEM) guidelines. ${ }^{8}$ Additionally, lack of guidance was noted in the guidelines about the acquisition rooms. For that reason, 20/34 of acquisition rooms complied with any guidelines (RCR, IPEM, AAPM and IAEA). ${ }^{3,4,6,8}$ Only 3/34 rooms were found with the illumination levels being less than 20 lux, this is the threshold recommended within the European Reference Organisation for Quality Assured Breast Screening and Diagnostic Services (EUREF). ${ }^{9} 17 / 34$ rooms had ambient light levels within the range of 25-50 lux, complying to ACR guidelines. ${ }^{13}$ However, 14/34 acquisition rooms were found to have very high ambient light levels above 50 lux. These rooms had no compliance to any regulatory body. Furthermore, as great variances were noted in the ambient light levels in the acquisition rooms, it was impossible to determine the optimal illumination level for these rooms. In the UK, breast screening units should be following the regulations from the RCR, IPEM and NHSBSP. ${ }^{6-8}$ Within these guidelines, differences are observed in the specification of monitors for the acquisition rooms and suitable room illumination levels. The NHSBSP propose a minimum of $1 \mathrm{MP}$ optimum resolution, when at the same time the RCR suggest monitors with $2 \mathrm{MP}$ resolution. ${ }^{6,7}$ In terms of the ambient light level, IPEM suggest that the illumination level should be above 15 lux, the RCR propose low ambient light level at 15lux for the reporting rooms and the NHSBSP suggest that high illumination levels should be avoided with no definition of the illuminance threshold. ${ }^{6-8}$ Meanwhile, no clear guidelines in terms of illumination levels are proposed for the acquisition rooms. They could follow the environmental guidelines for the reporting rooms but if this required adjusting the light level in the room between image acquisition and review, it may not be practical. Greater consideration to room design may be the solution but this would also have cost implications for the NHS. Further research is required to drive this type of change.

Additionally, in line with regulatory bodies it appears a trend that monitors with poor technical specifications, such as low optimum resolution (1-2MP) may be responsible for preventing the early detection of technical problems as artefacts and pathology because small or low-density micro calcification cancers or even larger lesions may be obscured. ${ }^{13}$ At the same time, artefacts may become difficult to be depicted during the time of the examination on monitors in the acquisition rooms. These factors may be responsible for an 
improper assessment of image quality, increasing the recalling rate of patients, increasing patient anxiety and cost for the NHS. ${ }^{[13-14]}$

Finally, a limitation to this work includes the fact that this was not an experimental study and as such there were many variables being considered at one point in time. Therefore, it was not possible to infer the effect of one individual variable (e.g. wall colour). This needs to be investigated in future work. Moreover, the geographical orientation of the rooms was not investigated during the survey. The room orientation might affect the ambient lighting and the presence of reflections during the day.

Further research is required to assess the impact of variations in monitor specification and the environment. In sub optimal conditions is still feasible that inadequate technical review may occur.

\section{CONCLUSION}

Good standards of monitor specifications and viewing conditions are factors which are required for the proper assessment of a mammographic image. Artefacts and small pathology may be missed in a sub-optimal environment of poor monitor specifications and viewing conditions. Vast differences in room layout in acquisition and reporting rooms are responsible for different illumination levels measured, in particular the location of natural and artificial light sources. This work has demonstrated that there is need for better standardisation and guidance for image review in acquisition rooms. This survey has highlighted substantial variation in monitor specification and room illumination levels.

A defined environment with the appropriate monitors could improve the quality assurance and quality control procedure and assist the technical evaluation of the mammographic images by the operators. With a standardised environment, it may be possible to reduce the number of technical recalls, as optimised image evaluation of technical quality may encourage repeat imaging at the time of first attendance, rather than recalling the patient. 


\section{REFERENCES}

1. National Health Service Screening \& Immunisations Team. Breast Screening Programme. 2019;17. Available via https://files.digital.nhs.uk/60/77DCCC/breastscreening-programme-eng-2017-18-report.pdf

2. Indrajit I, Verma B. Monitor displays in radiology: Part 1. Indian J Radiol Imaging. 2009;19:94-98. doi:10.4103/0971-3026.50819

3. Brettle DS. Display considerations for hospital-wide viewing of soft copy images. $\mathrm{Br} \mathrm{J}$ Radiol. 2007;80:503-507. doi:10.1259/bjr/26436784

4. American Association of Physicists in Medicine. Assessment of display performance for medical imaging systems: executive summary of AAPM TG18 report. Med Phys. 2005;32:1205-25. doi:10.1118/1.1861159

5. International Atomic Energy Agency. Quality Assurance Programme for Digital Mammography IAEA 2011. J Exp Psychol Gen. 2011;136:23-42.

6. The Royal College of Radiologists. Picture archiving and communication systems ( PACS ) and guidelines on diagnostic display devices. London. 3rd edition. 2019. Available via https://www.rcr.ac.uk/system/files/publication/field_publication_files/bfcr192_pacsdiagnostic-display.pdf

7. National Health Service Breast Screening Programme. Guidance on image display equipment for use in breast screening. December; 2010. NHSBSP publication no. 71.

8. Institute of Physics and Engineering in Medicine. Recommended Standards for the Routine Performance Testing of Diagnostic X-Ray Imaging Systems IPEM. 2005. https://doi.org/10.1038/s41413-018-0025-8. IPEM Report No. 91.

9. Perry N, Broeders M, De Wolf C, Törnberg S, Holland R, Von Karsa L. European Guidelines for Quality Assurance in Breast Cancer Screening and Diagnosis. 2013;19:1-432 Available via http://www.euref.org/european-guidelines

10. Papathanasiou S, Walton L A, Thompson J D. A systematic review of viewing conditions and monitor specifications in mammography. Radiography.2020;26:325331 doi: 10.1016/j.radi.2020.03.001.

11. Jones V, Phillips V. Routine quality control tests for full- field digital mammography systems Equipment report 1303 : fourth edition About the NHS Cancer Screening Programmes. 2013. Available via https://assets.publishing.service.gov.uk/government/uploads/system/uploads/attach ment_data/file/442720/nhsbsp-equipment-report-1303.pdf

12. RaySafe. RaySafe X2 Specifications. 2017. Available via http://mediabank.raysafe.com/downloadAsset.jsp?catalog=RaySafe+Media+Bank\&id $=1828$ \&encoding $=$ UTF- 8

13. American College of Radiology. Acr - Aapm - Siim Technical Standard for Electronic 
Practice of Medical Imaging. 2017;1076:1-18.

14. Ma W K, Borgen R, Kelly J, Millington S, Hilton B, Aspin R et al. Blurred digital mammography images: An analysis of technical recall and observer detection performance. Br J Radiol 2017;90:1071 https://doi.org/10.1259/bjr.20160271.

15. O'Rourke J, Mercer C, Starr L. Technical recall and image blur within a breast screening service. 2014. Available via https://sympmamm.org.uk/wp-

content/uploads/2017/09/conf-symp.2014.pdf 